\title{
Structural and magnetic properties of $\mathrm{UFe}_{6} \mathrm{Ga}_{6}$
}

\author{
A.P. Gonçalves ${ }^{\text {a,* }}$, J.C. Waerenborgh ${ }^{\text {a }}$, S. Sério ${ }^{\text {a }}$, J.A. Paixão ${ }^{b}$, M. Godinho ${ }^{\text {c }}$, M. Almeida ${ }^{\text {a }}$ \\ ${ }^{a}$ Departamento de Química, Instituto Tecnológico e Nuclear/CFMC-UL, Estrada Nacional, P-2686-953 Sacavém, Portugal \\ ${ }^{\mathrm{b}}$ Universidade de Coimbra, Faculdade de Ciências e Tecnologia, Dept. Física, CEMDRX, 3004-516 Coimbra, Portugal \\ ${ }^{\mathrm{c}}$ CFMC-UL/Dep., Física, FCUL, 1749-016 Campo Grande, Lisboa, Portugal
}

Received 11 May 2005; received in revised form 19 July 2005; accepted 11 September 2005

Available online 9 November 2005

\begin{abstract}
$\mathrm{UFe}_{6} \mathrm{Ga}_{6}$ polycrystalline samples were prepared by arc-melting, and single crystals were grown by the Czochralski method. This compound crystallizes in the orthorhombic $\mathrm{ScFe}_{6} \mathrm{Ga}_{6}$-type structure (space group Immm, $a=5.0560(4), b=8.5484(7)$ and $c=8.6914(7) \AA$ ), an ordered variant of the $\mathrm{ThMn}_{12}$-type structure. A ferromagnetic-type transition at $T_{\mathrm{C}}=530(5) \mathrm{K}$ is seen in the magnetization and A.C.-susceptibility measurements, and no other magnetic anomaly is observed down to $5 \mathrm{~K}$. Single crystal magnetization measurements along the three different crystallographic axes indicated $a$ as the easy direction, with a spontaneous magnetization $M_{\mathrm{S}}=12.3 \mu_{\mathrm{B}} / \mathrm{f}$.u. at $5 \mathrm{~K}$. The analysis of the ${ }^{57} \mathrm{Fe}$ Mössbauer spectroscopy data indicated magnetic hyperfine fields, $B_{\mathrm{hf}}$, significantly lower on $4 \mathrm{f}$ sites than on $8 \mathrm{k}$ sites, in agreement with the trend already observed on $\mathrm{UFe}_{x} \mathrm{Al}_{12-x}$, where the average $B_{\mathrm{hf}}$ were found to increase with the iron-iron interatomic distances.

(C) 2005 Elsevier Ltd. All rights reserved.
\end{abstract}

Keywords: A. Magnetic intermetallics; B. Crystal chemistry of intermetallics; B. Magnetic properties; Diffraction

\section{Introduction}

Intermetallic compounds of f-elements with the $\mathrm{ThMn}_{12^{-}}$ type structure and high iron content have been considered good candidates for hard magnetic materials [1,2]. The interaction between the $3 \mathrm{~d}$ and $\mathrm{f}$ electrons in a tetragonal structure frequently gives high uniaxial magnetocrystalline anisotropy, Curie temperature and saturation magnetization. However, binary $\mathrm{AFe}_{12}(\mathrm{~A}=\mathrm{f}$-element $)$ compounds do not exist, the partial substitution of iron by a third element being necessary to stabilise the $\mathrm{ThMn}_{12}$-type structure.

One of the most studied family of compounds with this structure is the $\mathrm{AFe}_{12-x} \mathrm{Al}_{x},(\mathrm{~A}=\mathrm{f}$-element) series [3-6]. The aluminium concentration necessary to stabilise the $\mathrm{ThMn}_{12^{-}}$ type structure is relatively high, usually higher than $50 \%$, but the study of these medium-low iron content compounds is fundamental for a better understanding of the contribution from the different magnetic sublattices to the magnetism.

The $\mathrm{UFe}_{12-x} \mathrm{Al}_{x}$ phase relations, previously explored by us, indicate a congruent melting composition range between $\mathrm{UFe}_{3.8} \mathrm{Al}_{8.2}$ and $\mathrm{UFe}_{5.8} \mathrm{Al}_{6.2}$ [7]. The $\mathrm{UFe}_{6} \mathrm{Al}_{6}$ alloy does not

\footnotetext{
* Corresponding author. Tel.: +351 1 9946182; fax: +351219941455.

E-mail address: apg@itn.pt (A.P. Gonçalves).
}

melt congruently but can be obtained by thermal treatment of polycrystalline samples. Measurements on $\mathrm{UFe}_{6} \mathrm{Al}_{6}$ samples indicate an easy-plane anisotropy and a ferromagnetic character with a Curie temperature $T_{\mathrm{C}} \sim 300 \mathrm{~K}$ [8]. In the closely related $\mathrm{UFe}_{6} \mathrm{Ga}_{6}$ compound only preliminary data reporting a Curie temperature of $T_{\mathrm{C}}=515 \mathrm{~K}$, much higher than the aluminium equivalent, was previously reported [9]. In order to enlighten the reason for this difference a careful investigation of $\mathrm{UFe}_{6} \mathrm{Ga}_{6}$ was performed. In the present paper, we report X-ray and neutron diffraction, ${ }^{57} \mathrm{Fe}$ Mössbauer spectroscopy and magnetisation measurements on this compound.

\section{Experimental}

Samples with $\mathrm{UFe}_{x} \mathrm{Ga}_{12-x}(5 \leq x \leq 6.5)$ nominal compositions were prepared by melting the stoichiometric amount of the elements (with purity of at least 99.9\%) in an induction furnace equipped with a levitation cold crucible and under an argon atmosphere. The samples were turned and remelted at least three times in order to ensure a better homogeneity. The final weight losses were less than $0.5 \mathrm{wt} \%$.

The microstructural analysis of the samples was performed using a scanning electron microscope (JEOL-JSM 840) on sample pieces embedded in resin and polished using $\mathrm{SiC}$ paper down to 4000 mesh. Quantitative analysis of the observed phases was made by energy dispersive spectroscopy (EDS) 
analysis of the atomic characteristic X-rays excited by the electron beam using an acceleration voltage of $30 \mathrm{keV}$ and a counting time of $100 \mathrm{~s}$.

$\mathrm{UFe}_{6} \mathrm{Ga}_{6}$ bulk charges with $\sim 15 \mathrm{~g}$ were prepared by melting in an induction furnace the stoichiometric amounts of the elements with purity of at least $99.9, \sim 20 \%$ of the material was pulled from the bulk charges using the Czochralski method, as previously described [7], in order to isolate small single crystals suitable for the X-ray characterization, and to obtain crystals appropriate for the study of the magnetic anisotropy.

Single crystals with $0.05 \times 0.05 \times 0.05 \mathrm{~mm}^{3}$ approximate dimensions were removed from the $\mathrm{UFe}_{6} \mathrm{Ga}_{6}$ pulled material, glued on the top of a glass fibre and transferred to a goniometer mounted on an Enraf-Nonius CAD-4 diffractometer with graphite monochromatized Mo K $\alpha$ radiation $(\lambda=0.71073 \AA)$. The unit-cell parameters were obtained from the least-squares refinement of the $2 \theta$ values of 25 strong and well centred reflections from the various regions of the reciprocal space in the $19^{\circ}<2 \theta<30^{\circ}$ range. The data set was collected at room temperature in a $\omega-2 \theta$ scan mode $(\Delta \omega=0.80+0.35 \tan \theta)$. Two reflections were monitored as orientation and as intensity standards at $4 \mathrm{~h}$ intervals during the data collection; no variation larger than $0.5 \%$ was observed. The intensities of the 6476 measured reflections (with $2 \theta<70^{\circ}$ ) were corrected for absorption using $\Psi$-scan, for polarisation and the Lorentz effects. The crystallographic and experimental data of the structural determination are listed in Table 1.

Powder neutron diffraction measurements were made at the TAS6 diffractometer installed at the DR3 reactor (Ris $\varnothing$ National Laboratory, Denmark) on a finely ground $\mathrm{UFe}_{6} \mathrm{Ga}_{6}$ sample of $\sim 30 \mathrm{~g}$ encapsulated in a vanadium can. The TAS6 instrument is equipped with a bank of 15 detectors covering an angular range of $120^{\circ}$ and the data were collected with a constant $2 \theta$ step of $0.0529^{\circ}$. The incident beam was monochromated by Bragg reflections from the (311) face of a germanium single crystal, selecting a wavelength of $1.0697 \AA$. A pyrolitic graphite filter was inserted after the monochromator to suppress high-order harmonics.

Magnetic measurements were performed on polycrystalline samples and oriented crystals (with $0.5 \times 0.5 \times 0.5 \mathrm{~mm}^{3}$ approximate dimensions) using a SQUID magnetometer (Quantum Design, MPMS) in the 2-400 K temperature range under fields up to $5.5 \mathrm{~T}$, and a vibrating sample magnetometer (VSM) for temperatures between 300 and $1000 \mathrm{~K}$.

Mössbauer spectra were measured in transmission mode using a conventional constant-acceleration spectrometer and a $25 \mathrm{mCi}{ }^{57} \mathrm{Co}$ source in a $\mathrm{Rh}$ matrix. The velocity scale was calibrated using an $\alpha$-Fe foil at room temperature. Mössbauer absorbers were prepared from a fraction of the same sample used for neutron diffraction, which was pressed together with lucite powder into perspex holders, in order to obtain homogeneous and isotropic absorbers containing about $5 \mathrm{mg} / \mathrm{cm}^{2}$ of natural iron. Spectra were obtained at 295 and $5 \mathrm{~K}$. Low-temperature measurements were performed using a liquid-nitrogen/liquid-helium flow cryostat, temperature
Table 1

Details of single crystal X-ray diffraction measurements

\begin{tabular}{ll}
\hline Chemical formula & $\mathrm{UFe}_{6} \mathrm{Ga}_{6}$ \\
\hline Formula weight & $991.43 \mathrm{~g} / \mathrm{mol}$ \\
Crystal system & Orthorhombic \\
Space group [11] & Immm (No.71) \\
$a$ & $5.042(4) \AA$ \\
$b$ & $8.510(8) \AA$ \\
$c$ & $8.637(7) \AA$ \\
$V$ & $370.6(5) \AA^{3}$ \\
$Z$ & 2 \\
$D_{\text {calc }}$ & $8.88 \mathrm{~g} \mathrm{~cm}{ }^{-1}$ \\
$\mu$ (Mo K $\alpha)$ & $49.43 \mathrm{~cm}^{2} \mathrm{~g}^{-1}$ \\
Approximate crystal dimensions & $0.05 \times 0.05 \times 0.05 \mathrm{~mm}^{3}$ \\
Radiation, wavelength & Mo K $\alpha, 0.71073 \AA$ \\
Monochromator & $\mathrm{Graphite}$ \\
Temperature & $295 \mathrm{~K}$ \\
$\theta$ range & $1.5-35^{\circ}$ \\
$\omega 2 \theta$ scan & $\Delta \omega=0.80+0.35 \mathrm{tan} \theta$ \\
Data set & $-8 \leq h \leq 8,-13 \leq k \leq 13$, \\
& $-13 \leq l \leq 13$ \\
Crystal-to-receiving-aperture distance & $173 \mathrm{~mm}$ \\
Horizontal, vertical aperture & $4,4 \mathrm{~mm}$ \\
Total data & 6476 \\
Unique data & 475 \\
Observed data $(I \geq 3 \sigma(I))$ & 428 \\
Number of refined parameters & 35 \\
$F i n a l$ agreement $f a c t o r s$ \\
$R=\sum\left|F_{\text {obs }}-F_{\text {calc }}\right| / \sum\left|F_{\text {obs }}\right|$ & \\
$w R=\left[\sum\left(w\left(\left|F_{\text {obs }}\right|-\left|F_{\text {calc }}\right|\right)^{2}\right) / w\left|F_{\text {obs }}\right|^{2}\right]^{1 / 2}$ & 0.115 \\
$S=\left[\Sigma w\left(\left|F_{\text {obs }}\right|-\left|F_{\text {calc }}\right|\right)^{2} /(m-n)\right]^{1 / 2}$ & 0.994 \\
\hline
\end{tabular}

${ }^{\text {a }} m$, number of observations; $n$, number of variables.

stability $\pm 0.5 \mathrm{~K}$. The spectra were fitted to Lorentzian lines using a non-linear least-squares computer method [10].

\section{Results and discussion}

The microstructural study of the samples indicated that the only nominal composition that melts congruently is $\mathrm{UFe}_{6} \mathrm{Ga}_{6}$. EDS analysis shows an $\mathrm{UFe}_{5.6(5)} \mathrm{Ga}_{6.4(5)}$ composition, close to the nominal U:6Fe:6Ga ratio of the elements. Samples with lower iron concentration contain an intergranular phase, identified as $\mathrm{FeGa}_{3}$ by EDS. For higher iron compositions the formation of an eutectic between the $\mathrm{UFe}_{6} \mathrm{Ga}_{6}$ grains is observed. EDS elemental analysis indicates that this eutectic is composed by $\mathrm{UFe}_{6} \mathrm{Ga}_{6}$ and $\mathrm{Fe}_{3} \mathrm{Ga}_{4}$.

Single crystal X-ray diffraction data were used to refine the cell parameters in the orthorhombic system to $a=5.042$ (4), $b=8.510(8), c=8.637(7) \AA$. Careful examination of the data led to the possible $I 222, I 2{ }_{1} 2_{1}{ }_{2}, I m m 2, I m 2 \mathrm{~m}, I 2 \mathrm{~mm}$ and $I \mathrm{mmm}$ space groups [11] for the $\mathrm{UFe}_{6} \mathrm{Ga}_{6}$ alloy. Immm was found to be the most correct during the refinement. The structure was solved by the Patterson function, employing the program SHELXs-97 [12], which allowed the determination of the uranium atoms position. The iron and gallium atoms were located using the difference Fourier synthesis. The program SHELXL-97 [12] was further employed to refine the $\mathrm{UFe}_{6} \mathrm{Ga}_{6}$ crystal structure. The extinction factor, scale factor, five occupation factors, four position parameters $(y$ for the $4 \mathrm{~g}$ 
Table 2

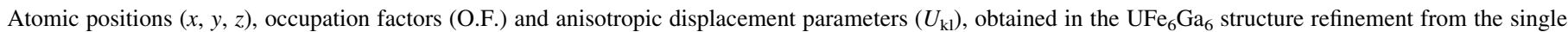
crystal X-ray data

\begin{tabular}{|c|c|c|c|c|c|c|c|c|c|c|c|c|}
\hline Atom & $\begin{array}{l}\text { Wyckoff } \\
\text { position }\end{array}$ & $X$ & $Y$ & $z$ & O.F. & $U_{11}(\AA)$ & $U_{22}(\AA)$ & $U_{33}(\AA)$ & $U_{23}(\AA)$ & $U_{13}(\AA)$ & $U_{12}(\AA)$ & $U_{\text {eq }}(\AA)$ \\
\hline U1 & $2 \mathrm{a}$ & 0 & 0 & 0 & 1(fixed) & 0.009 & 0.008 & 0.001 & 0 & 0 & 0 & 0.006 \\
\hline Ga1 & $4 \mathrm{e}$ & 0 & 0 & 0.3465 & 1.00 & 0.014 & 0.006 & 0.000 & 0 & 0 & 0 & 0.007 \\
\hline $\mathrm{Fe} 1$ & $4 \mathrm{f}$ & 0 & $1 / 2$ & 0.3059 & 1.25 & 0.012 & 0.004 & 0.014 & 0 & 0 & 0 & 0.010 \\
\hline $\mathrm{Ga} 2$ & $4 g$ & 0 & 0.3438 & 0 & 0.99 & 0.014 & 0.010 & 0.015 & 0 & 0 & 0 & 0.008 \\
\hline $\mathrm{Ga} 3$ & $4 \mathrm{~h}$ & 0.5 & 0.7677 & 0 & 0.83 & 0.010 & 0.019 & 0.014 & 0 & 0 & 0 & 0.010 \\
\hline $\mathrm{Fe} 2$ & $8 \mathrm{k}$ & $1 / 4$ & $1 / 4$ & $1 / 4$ & 1.08 & 0.010 & 0.008 & 0.025 & 0.000 & 0.000 & 0.000 & 0.007 \\
\hline
\end{tabular}

Table 3

Results of the structure refinement from the neutron data

\begin{tabular}{|c|c|c|c|c|c|c|}
\hline Atom & Position & $x$ & $Y$ & $z$ & O.F. & $U \times 10^{2}\left(\AA^{2}\right)$ \\
\hline U1 & $2 \mathrm{a}$ & 0 & 0 & 0 & 1 & $0.18(6)$ \\
\hline Ga1 & $4 \mathrm{e}$ & 0 & 0 & $0.3432(5)$ & 1 & $0.57(6)$ \\
\hline $\mathrm{Fe} 1$ & $4 f$ & 0 & $1 / 2$ & $0.2656(5)$ & 1 & $0.43(6)$ \\
\hline $\mathrm{Ga} 2$ & $4 \mathrm{~g}$ & 0 & $0.3468(6)$ & 0 & 1 & $0.34(7)$ \\
\hline $\mathrm{Ga} 3$ & $4 h$ & 0.5 & $0.8051(6)$ & 0 & 1 & $0.53(7)$ \\
\hline $\mathrm{Fe} 2$ & $8 \mathrm{k}$ & $1 / 4$ & $1 / 4$ & $1 / 4$ & 1 & $0.18(3)$ \\
\hline
\end{tabular}

Parameters defined as in Table 2.

and $4 \mathrm{~h}$ sites, and $z$ for the $4 \mathrm{e}$ and $4 \mathrm{f}$ sites), and 24 anisotropic displacement parameters, a total of 35 parameters, were refined, the final results pointing to a crystallization in the orthorhombic $\mathrm{ScFe}_{6} \mathrm{Ga}_{6}$-type structure, space group Immm. However, it was not possible to reduce the residuals below $11 \%$, and the final results had unrealistic occupation factors. A detailed analysis of the data profiles showed that many peaks had a double structure, indicating the existence of twining due to the similarity between $b$ and $c$ cell parameters.

In order to refine the $\mathrm{UFe}_{6} \mathrm{Ga}_{6}$ crystal structure neutron diffraction experiments were performed. The structure was refined by the Rietveld method [13] using as a starting model the $\mathrm{ScFe}_{6} \mathrm{Ga}_{6}$-type structure and the cell parameters found in the single crystal X-ray diffraction study (Tables 1 and 2). The reflection profiles were modelled by a pseudo-Voigt function, and an asymmetry parameter was included for $2 \theta<40^{\circ}$. The structure refinement converged to the $R_{\mathrm{F}}=0.043, R_{\mathrm{W}}=0.061$ final residuals, with $a=5.0560(4), b=8.5484(7)$ and $c=$ 8.6914(7) $\AA$, and the parameter values presented in Table 3 . In Fig. 1, the experimental powder neutron diffractogram is plotted, together with the calculated and difference profiles. No unindexed lines were found in the spectrum, as expected for a single-phase material, confirming the $\mathrm{ScFe}_{6} \mathrm{Ga}_{6}$-type structure for $\mathrm{UFe}_{6} \mathrm{Ga}_{6}$. The ferromagnetic ordering below $530(5) \mathrm{K}$ agrees with this (confirming the same magnetic and structural unit cells), but points to an increase of the peaks intensity below the Curie temperature. However, no magnetic contributions were considered in the refinement due to their small value when compared to the intensity of the crystallographic peaks.

The $\mathrm{ScFe}_{6} \mathrm{Ga}_{6}$-type is a body-centred orthorhombic structure type derived from the $\mathrm{ThMn}_{12}$ according to the sequence $I 4 / \mathrm{mmm} \rightarrow\left(t_{2} ; c b a\right) \rightarrow I m m m$. It is an ordered variant of the $\mathrm{ThMn}_{12}$-type structure, which results from the splitting $8 \mathrm{i} \rightarrow 4 \mathrm{e}, 4 \mathrm{~g}$ and $8 \mathrm{j} \rightarrow 4 \mathrm{f}, 4 \mathrm{~h}$, the $8 \mathrm{f}$ becoming the $8 \mathrm{k}$ site, the iron atoms only occupying the $8 \mathrm{k}$ and $4 \mathrm{f}$ sites (Fig. 2).

The number of nearest neighbours and interatomic distances (up to $3.40 \AA$ ), obtained from the neutron diffraction refinement of the different crystallographic positions, are listed in Table 4. The coordination numbers (C.N.), deduced using the maximum-gap method [14], are 20 for $\mathrm{U}(2 \mathrm{a}), 14$ for $\mathrm{Ga} 1(4 \mathrm{e})$ and $\mathrm{Ga} 2(4 \mathrm{~g}), 13$ for Ga3(4 h), and 12 for Fe1(4f) and $\mathrm{Fe} 2(8 \mathrm{k})$.

Considering the metallic radii of the elements for a coordination number of $12,1.26 \AA$ for iron, $1.39 \AA$ for gallium and $1.53 \AA$ for uranium [15], and the calculated interatomic distances, all the U(2a) - (nearest neighbours) distances are above the sum of their radii, which is partially explained by its higher coordination number. These high U(2a)-(nearest neighbours) distances, as well as the $5.04 \AA$ uranium-uranium shortest distance, well above the Hill limit $\sim 3.4 \AA$, suggest the

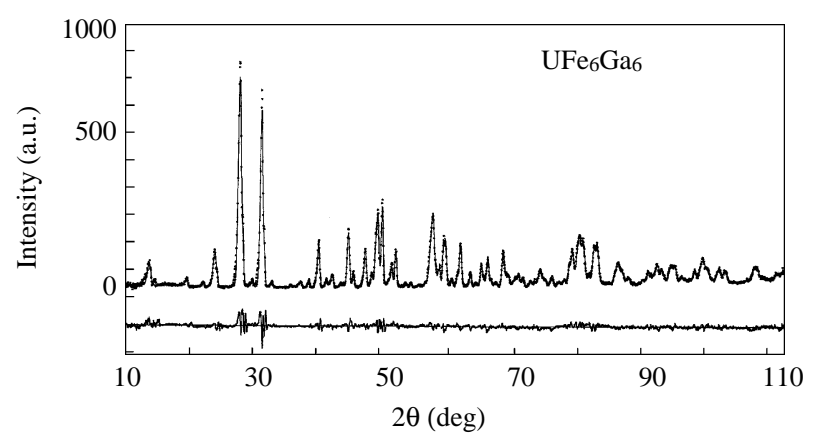

Fig. 1. Experimental, calculated and differential $\mathrm{UFe}_{6} \mathrm{Ga}_{6}$ neutron powder diffraction profiles. 

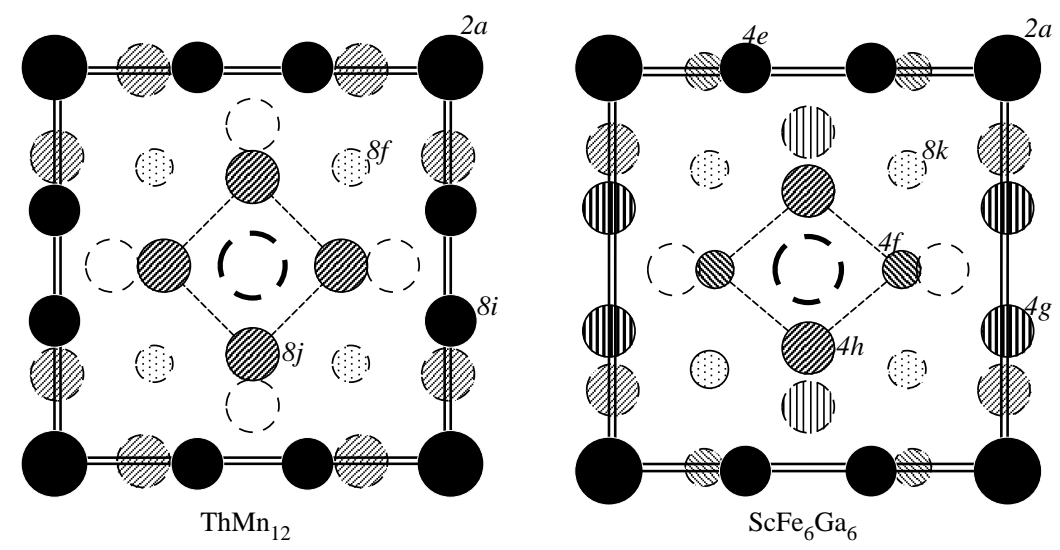

Fig. 2. Projections of the $\mathrm{ThMn}_{12}$ and $\mathrm{ScFe}_{6} \mathrm{Ga}_{6}$-type structures along the $c$ and $a$ axes, respectively.

possibility of a significant uranium magnetic moment in $\mathrm{UFe}_{6} \mathrm{Ga}_{6}$.

The interatomic distances between the $\mathrm{Fe}$ atoms and the nearest-iron/gallium positions $(2.517-2.637 \AA$ ) are lower or approximately equal to the metallic radii sum, in contrast to the interatomic distances with uranium. The remaining atoms have interatomic distances lower, equal or higher than the sum of the metallic radii. The gallium atoms usually have iron neighbours at distances below and gallium neighbours at distances above the sum of their metallic radii. It is interesting to notice that all the iron-iron interatomic distances are very close to the sum of the metallic radii, pointing for the possibility of predominant $\mathrm{Fe}-\mathrm{Fe}$ ferromagnetic interactions. This contrasts with the $\mathrm{UFe}_{6} \mathrm{Al}_{6}$ compound, where the $\mathrm{Fe}(8 \mathrm{f})-\mathrm{Fe}(8 \mathrm{f})$ distances, $2.507 \AA[8]$, are below the sum of the metallic radii and lead to antiferromagnetic interactions opposing the predominant ferromagnetic $\mathrm{Fe}(8 \mathrm{f})-\mathrm{Fe}(8 \mathrm{j})$ and $\mathrm{Fe}(8 \mathrm{j})-\mathrm{Fe}(8 \mathrm{j})$ interactions [16]. On the contrary, the longer iron-iron distances on the $8 \mathrm{k}$ sites in $\mathrm{UFe}_{6} \mathrm{Ga}_{6}$ may reinforce the ferromagnetic interactions, as already proposed for the 3-d magnetic properties in $\mathrm{UFe}_{x} \mathrm{Al}_{12-x}[16]$ and other uranium $\mathrm{ThMn}_{12^{-}}$ type compounds such as the $\mathrm{UFe}_{10} \mathrm{X}_{2}(\mathrm{X}=\mathrm{Si}, \mathrm{Mo}, \mathrm{Re})$ [17].

The temperature dependence of the $\mathrm{UFe}_{6} \mathrm{Ga}_{6}$ magnetization, measured under 100 Oe after zero field cooling a bulk polycrystalline sample, is shown in Fig. 3. A ferromagnetictype transition is seen at $T_{\text {ord }}=530(5) \mathrm{K}$, value corresponding to the minimum of the temperature derivative of the susceptibility. $T_{\text {ord }}$ was confirmed by A.C.-susceptibility measurements that show a peak at 537(6) $\mathrm{K}$ in the real component (insert in Fig. 3). No other magnetic transition is seen down to $5 \mathrm{~K}$. Ordering temperatures close to the $560 \mathrm{~K}$ were previously reported for $\mathrm{LuFe}_{5.8} \mathrm{Ga}_{6.2}$, which has the highest observed $T_{\text {ord }}$ in the $\mathrm{LnFe}_{6-x} \mathrm{Ga}_{6+x}$ ( $\mathrm{Ln}=$ lanthanide, Y) family of compounds [18], where magnetic order is established at temperatures above $T_{\mathrm{C}} \sim 400 \mathrm{~K}$. Moreover, for $\mathrm{UFe}_{6} \mathrm{Ga}_{6}$ the transition temperature is much higher than the $\mathrm{UFe}_{6} \mathrm{Al}_{6}$ Curie temperature, $T_{\mathrm{C}} \sim 300 \mathrm{~K}$ [8]. In iron-containing $\mathrm{R}_{x} \mathrm{Fe}_{y}$ compounds the Curie temperature is mainly determined by the $\mathrm{Fe}-\mathrm{Fe}$ sublattice interactions. In a first approximation, the same dependence is also found in $\mathrm{UFe}_{6} \mathrm{X}_{6}(\mathrm{X}=\mathrm{Al}, \mathrm{Ga})$. As

Table 4

$\mathrm{UFe}_{6} \mathrm{Ga}_{6}$ interatomic distances $(d)$ and nearest neighbours (NN) average numbers

\begin{tabular}{|c|c|c|c|c|c|c|c|}
\hline & NN & Atoms & $d(\AA)$ & & $\mathrm{NN}$ & Atoms & $d(\AA)$ \\
\hline \multirow[t]{5}{*}{$\mathrm{U}(2 \mathrm{a})$} & 2 & $\mathrm{Ga} 1(4 \mathrm{e})$ & $2.934(3)$ & $\mathrm{Ga} 2(4 \mathrm{~g})$ & 4 & $\mathrm{Fe} 2(8 \mathrm{k})$ & $2.622(3)$ \\
\hline & 2 & $\mathrm{Ga} 2(4 \mathrm{~g})$ & $3.014(4)$ & & 2 & $\mathrm{Fe} 1(4 \mathrm{f})$ & $2.632(6)$ \\
\hline & 4 & $\mathrm{Ga} 3(4 \mathrm{~h})$ & $3.043(3)$ & & 1 & $\mathrm{Ga} 2(4 \mathrm{~g})$ & $2.663(8)$ \\
\hline & 8 & $\mathrm{Fe} 2(8 \mathrm{k})$ & $3.2994(2)$ & & 1 & $\mathrm{U}(2 \mathrm{a})$ & $3.014(4)$ \\
\hline & & & & & 4 & $\mathrm{Ga1}(4 \mathrm{e})$ & $3.156(6)$ \\
\hline \multirow[t]{4}{*}{$\mathrm{Ga} 1(4 \mathrm{e})$} & 4 & $\mathrm{Fe} 2(8 \mathrm{k})$ & $2.637(4)$ & Ga3(4h) & 4 & $\mathrm{Fe} 2(8 \mathrm{k})$ & $2.529(3)$ \\
\hline & 1 & $\mathrm{U}(2 \mathrm{a})$ & $2.934(3)$ & & 2 & $\mathrm{Ga1}(4 \mathrm{e})$ & $2.971(6)$ \\
\hline & 2 & $\mathrm{Ga} 3(4 \mathrm{~h})$ & $2.971(6)$ & & 2 & $\mathrm{U}(2 \mathrm{a})$ & $3.043(3)$ \\
\hline & 4 & $\mathrm{Ga} 2(4 \mathrm{~g})$ & $3.156(6)$ & & 1 & Ga3(4h) & $3.386(7)$ \\
\hline \multirow[t]{3}{*}{$\mathrm{Fe} 1(4 \mathrm{f})$} & 4 & $\mathrm{Fe} 2(8 \mathrm{k})$ & $2.517(4)$ & $\mathrm{Fe} 2(8 \mathrm{k})$ & 2 & $\mathrm{Fe} 1(4 \mathrm{f})$ & $2.517(4)$ \\
\hline & 2 & $\mathrm{Ga} 3(4 \mathrm{~h})$ & $2.624(7)$ & & 2 & $\mathrm{Fe} 2(8 \mathrm{k})$ & $2.5280(3)$ \\
\hline & 2 & $\mathrm{Ga} 2(4 \mathrm{~g})$ & $2.632(6)$ & & 2 & Ga3(4h) & $2.529(3)$ \\
\hline
\end{tabular}




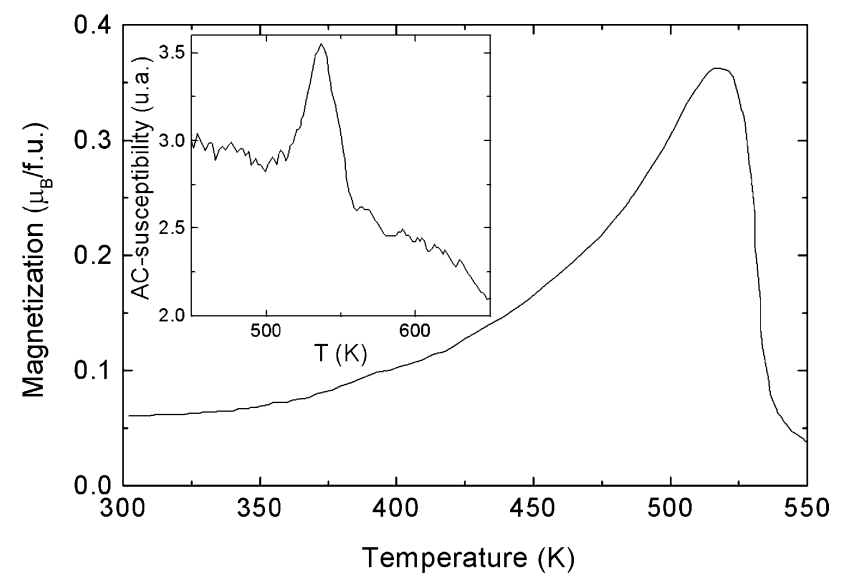

Fig. 3. Temperature dependence of the magnetization of an $\mathrm{UFe}_{6} \mathrm{Ga}_{6}$ polycrystalline sample for an applied field of 100 Oe. The insert show the A.C.-susceptibility as a function of temperature curve for the same sample.

the number of iron nearest-neighbours is in average the same for both compounds, the significant difference between $\mathrm{UFe}_{6} \mathrm{Al}_{6}$ and $\mathrm{UFe}_{6} \mathrm{Ga}_{6}$ Curie temperatures points to a decisive influence of the $\mathrm{Fe}-\mathrm{Fe}$ interatomic distances, in agreement with the crystallographic analysis described above. The significantly higher ordering temperature on $\mathrm{UFe}_{6} \mathrm{Ga}_{6}$ as compared to $\mathrm{UFe}_{6} \mathrm{Al}_{6}$ is probably related to the fact that the shortest ironiron distances in $\mathrm{UFe}_{6} \mathrm{Ga}_{6}$ are larger than those in $\mathrm{UFe}_{6} \mathrm{Al}_{6}$ [8].

The magnetization versus magnetic field previously measured at $5 \mathrm{~K}$ for both free powder and powder fixed samples [9] evidence a saturation magnetization $\left(M_{0}\right)$, obtained from the linear extrapolation of $M(\mathrm{H} \rightarrow 0)$, for $\mathrm{UFe}_{6} \mathrm{Ga}_{6}$ of $M_{0}^{\text {free }}=10.5 \mu_{\mathrm{B}} /$ f.u., in the case of the free powder, and $M_{0}^{\text {fixed }}=4.1 \mu_{\mathrm{B}} /$ f.u. for the fixed powder. The ratio $M_{0}^{\text {fixed }}(\mathrm{T} \rightarrow 0) / M_{0}^{\text {free }}(\mathrm{T} \rightarrow 0)$, which gives a valuable information on the magnetic anisotropy of the compound [19] is in this case approximately 0.4 indicating a predominant uniaxial anisotropy. In order to clarify this point and to better characterize the magnetic properties of this compound single crystal measurements were performed.

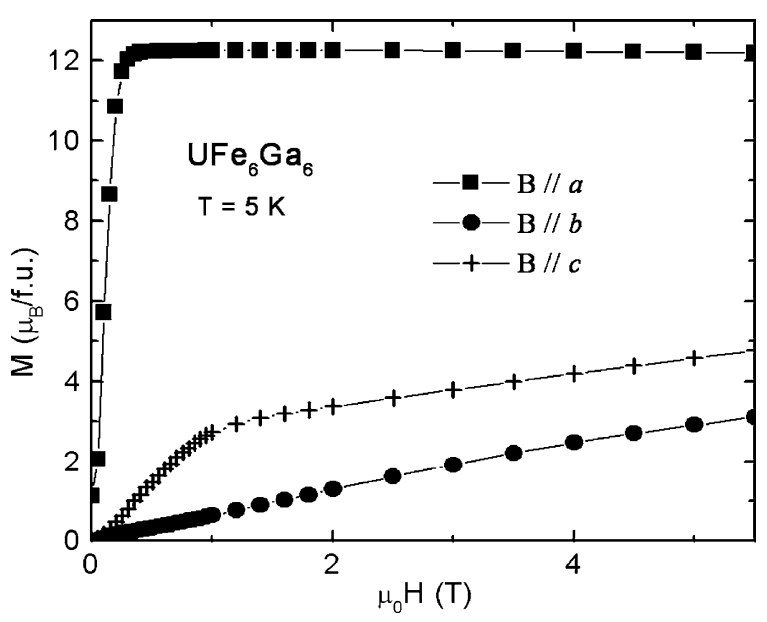

Fig. 4. Magnetization versus field along the three crystallographic directions of the $\mathrm{UFe}_{6} \mathrm{Ga}_{6}$ single crystal at $5 \mathrm{~K}$.

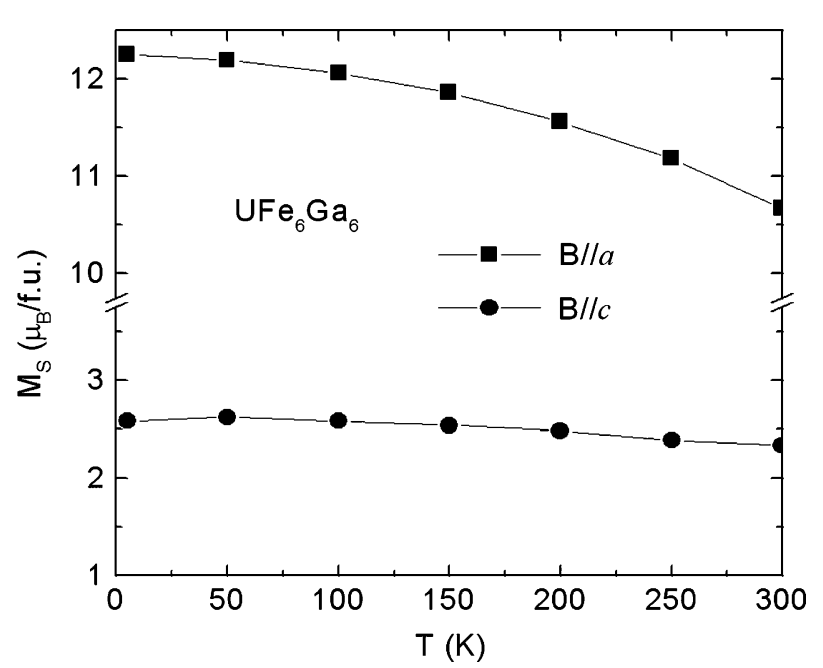

Fig. 5. Spontaneous magnetization of the $\mathrm{UFe}_{6} \mathrm{Ga}_{6}$ single crystal along $a$ and $c$ axes, as a function of temperature.

Small samples chosen from the $\mathrm{UFe}_{6} \mathrm{Ga}_{6}$ pulled material were tested by X-ray diffraction in order to check their single crystalline character. Most of them had both twined domains with similar volume, but a few showed a clear predominance of only one of the domains (ratio bigger than 10:1). The magnetization measurements were made on one of these single crystals, with $0.5 \times 0.5 \times 0.5 \mathrm{~mm}^{3}$ approximate dimensions. The single crystal magnetisation measurements along the three different crystallographic axes confirmed the uniaxial anisotropy previously suggested from the $M_{0}^{\text {fixed }}(\mathrm{T} \rightarrow 0) / M_{0}^{\text {free }}(\mathrm{T} \rightarrow$ 0 ) ratio (Fig. 4). The $a$ axis is the easy direction, the magnetisation curves with the field parallel to this direction presenting a typical ferromagnetic behaviour, with the saturation being reached for fields $\sim 0.25 \mathrm{~T}$. It is important to notice that this $a$ axis correspond to the $c$ axis in the $\mathrm{ThMn}_{12^{-}}$ type structure. Therefore, the $a$ easy axis in $\mathrm{UFe}_{6} \mathrm{Ga}_{6}$ is in clear contrast with the behaviour observed in $\mathrm{UFe}_{6} \mathrm{Al}_{6}$, which has $a$ and $b$ as the easy directions [8], and with the $\mathrm{RFe}_{12-x} \mathrm{Ga}_{x}(\mathrm{R}=$ rare earth) alloys, where an easy-plane type anisotropy was also reported [18].

The measurements performed with applied fields parallel to the $b$ direction show a linear variation of the magnetisation with field, without saturation up to $5.5 \mathrm{~T}$ (Fig. 4). With an estimated anisotropy field, given by the intersection of the extrapolated $b$ hard direction magnetisation curve with the $a$ easy one, of $\sim 25 \mathrm{~T}$ at $5 \mathrm{~K}$, indicating a high magnetic anisotropy. The magnetisation measurements performed with applied fields parallel to the $\mathrm{c}$ direction show an initial increase up to $1 \mathrm{~T}\left(2.7 \mu_{\mathrm{B}} /\right.$ f.u. $)$, followed by a linear variation with magnetic field, without saturation up to $5.5 \mathrm{~T}$. The predicted anisotropy field for this direction is also $\sim 25 \mathrm{~T}$ at $5 \mathrm{~K}$.

The variation of the spontaneous magnetisation, $M_{\mathrm{S}}$, with temperature, obtained from the extrapolation to $H=0$ of the isothermal magnetisation curves measured along the easy direction, for fields applied parallel to the a and c directions, is presented in Fig. 5. For the measurements along $a$ value of $12.3 \mu_{\mathrm{B}} /$ f.u.is obtained at $5 \mathrm{~K}$. This value is higher than the values obtained for the nonmagnetic rare earth $\mathrm{YFe}_{6} \mathrm{Ga}_{6}$ and 


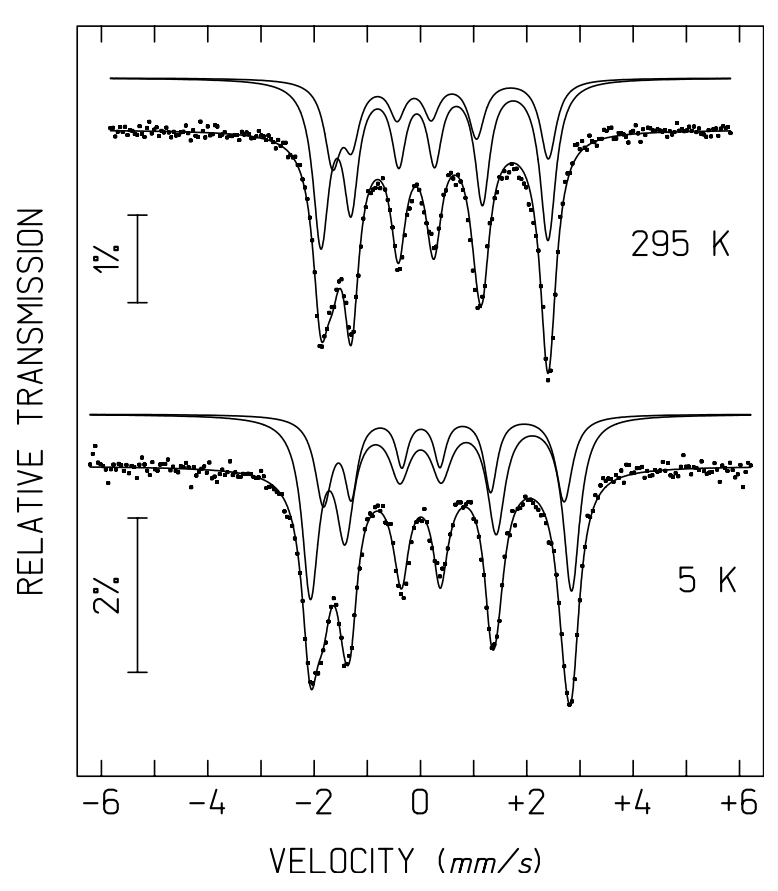

Fig. 6. Mössbauer spectra of $\mathrm{UFe}_{6} \mathrm{Ga}_{6}$ at 295 and $5 \mathrm{~K}$.

$\mathrm{LuFe}_{5.8} \mathrm{Ga}_{6.2}$ phases with $\mathrm{ThMn}_{12}$-type structure (8.6 and $10.6 \mu_{\mathrm{B}}$ /f.u., respectively) [18], the value observed in $\mathrm{UFe}_{5.8} \mathrm{Al}_{6.2}\left(10.4 \mu_{\mathrm{B}}\right.$ /f.u. $)$ [8] and much higher than the 3.9 and $2.5 \mu_{\mathrm{B}} /$ f.u. values observed for the $\mathrm{ScFe}_{6} \mathrm{Ga}_{6}$-type structure $\mathrm{YFe}_{6} \mathrm{Ga}_{6}$ and $\mathrm{LuFe}_{5.8} \mathrm{Ga}_{6.2}$ alloys [18] that have been reported as ferrimagnets. This difference can be due to the existence of a high uranium magnetic contribution ferromagnetically aligned with the iron magnetic sublattice, significantly higher iron magnetic moments, or a combination of both previous factors. The spontaneous magnetisation along a decreases from $12.3 \mu \mathrm{B} /$ f.u. at $5 \mathrm{~K}$ to $10.7 \mu \mathrm{B} / \mathrm{f}$.u. at $300 \mathrm{~K}$, pointing to a high Curie temperature, in agreement with the above referred results obtained for polycrystalline samples (Fig. 3). For the measurements with the field parallel to $c$ only a slight decrease from 2.6 to $2.3 \mu_{\mathrm{B}} /$ f.u. between 5 and $300 \mathrm{~K}$ is observed.

The Mössbauer spectra of $\mathrm{UFe}_{6} \mathrm{Ga}_{6}$ at different temperatures are shown in Fig. 6. The spectra were fitted with two sextets and the estimated relative areas, both at 295 and $5 \mathrm{~K}$ (Table 5), are consistent with the iron site occupation factors deduced from the powder diffraction data (Table 3 ). The sextet

Table 5

Estimated parameters from the Mössbauer spectra of $\mathrm{UFe}_{6} \mathrm{Ga}_{6}$ taken at different temperatures

\begin{tabular}{lllllll}
\hline$T(\mathrm{~K})$ & Site & $\delta(\mathrm{mm} / \mathrm{s})$ & $\varepsilon(\mathrm{mm} / \mathrm{s})$ & $B_{\mathrm{hf}}(\mathrm{T})$ & $\Gamma(\mathrm{mm} / \mathrm{s})$ & $I(\%)$ \\
\hline 295 & $8 \mathrm{k}$ & 0.19 & 0.34 & 13.4 & 0.38 & 67 \\
& $4 \mathrm{f}$ & 0.20 & 0.49 & 12.8 & 0.37 & 33 \\
5 & $8 \mathrm{k}$ & 0.31 & 0.38 & 15.1 & 0.37 & 66 \\
& $4 \mathrm{f}$ & 0.34 & 0.45 & 14.1 & 0.44 & 34 \\
\hline
\end{tabular}

$\delta$, isomer shift relative to metallic iron; $\varepsilon=\left(\mathrm{e}^{2} \mathrm{~V}_{\mathrm{ZZ}} \mathrm{Q} / 4\right)\left(3 \cos ^{2} \theta-1\right)$, quadrupole shift; $B_{\mathrm{hf}}$, magnetic hyperfine field; $\Gamma$, line width; $I$, relative area. Errors are $<0.02 \mathrm{~mm} / \mathrm{s}$ for $\delta, \varepsilon$ and $I ;<0.1 \mathrm{~T}$ for $B_{\mathrm{hf}}$ and $<2 \%$ for $I$. with the higher I is therefore attributed to $\mathrm{Fe}(8 \mathrm{k})$ and the other to $\mathrm{Fe}(4 \mathrm{f})$. The isomer shifts, $\delta$, are slightly lower in $8 \mathrm{k}$ sites than in $4 \mathrm{f}$ sites, although the differences are still within experimental error, as expected [20] considering that the number of iron nearest neighbours is the same for both sites (Table 4). The temperature variations of the estimated $\delta$ are explained by the second-order Doppler shift. The magnetic hyperfine fields in $\mathrm{UFe}_{6} \mathrm{Ga}_{6}, B_{\mathrm{hf}}$, are significantly higher than the averaged $B_{\mathrm{hf}}$ in $\mathrm{UFe}_{5.8} \mathrm{Al}_{6.2}$ [20]. Since higher $B_{\mathrm{hf}}$ are related to higher $\mu_{\mathrm{B}}$ [20], this result is consistent with the higher spontaneous magnetization of $\mathrm{UFe}_{6} \mathrm{Ga}_{6}$, when compared to that observed in $\mathrm{UFe}_{5.8} \mathrm{Al}_{6.2}$. On the other hand, $B_{\mathrm{hf}}$ are significantly lower on $4 \mathrm{f}$ sites than on $8 \mathrm{k}$ sites. Considering the average $\mathrm{Fe}-\mathrm{Fe}$ interatomic distances, $d_{\mathrm{Fe}-\mathrm{Fe}}$, for each site (Table 4) this agrees with the trend already observed for the closely related $\mathrm{UFe}_{x} \mathrm{Al}_{12-x}$ intermetallics, where the average $B_{\mathrm{hf}}$ were found to increase with $d_{\mathrm{Fe}-\mathrm{Fe}}$ [20].

\section{Conclusions}

$\mathrm{UFe}_{6} \mathrm{Ga}_{6}$ is the only known uranium compound crystallizing in the $\mathrm{ScFe}_{6} \mathrm{Ga}_{6}$-type structure. Comparing with the closely related uranium-containing compounds crystallizing in the $\mathrm{ThMn}_{12}$-type structure, $\mathrm{UFe}_{6} \mathrm{Ga}_{6}$ has the second highest ordering temperature, only lower than that of $\mathrm{UFe}_{10} \mathrm{Si}_{2}$ $(640 \mathrm{~K})$. The high ordering temperature in $\mathrm{UFe}_{10} \mathrm{Si}_{2}$ was explained by its high iron concentration and by the silicon partial occupation of the $8 \mathrm{f}$ sites and full occupation by iron of the $8 \mathrm{j}$ and $8 \mathrm{i}$ sites, which have the highest $d_{\mathrm{Fe}-\mathrm{Fe}}$. On the other hand, the high ordering temperature in $\mathrm{UFe}_{6} \mathrm{Ga}_{6}$ is probably due to the high $d_{\mathrm{Fe}-\mathrm{Fe}}, \geq 2.517 \AA$. Comparison with isostructural rare-earth containing compounds is not easy since, as far as we know, interatomic distances are not available in the literature for those compounds. It should also be noticed that $\mathrm{UFe}_{10} \mathrm{Si}_{2}$ and $\mathrm{UFe}_{6} \mathrm{Ga}_{6}$, in addition to having the highest ordering temperatures, also have the higher saturation magnetization per iron atom and are the only compounds of this family with uniaxial anisotropy. Furthermore, they have the same easy axis, since the $a$-axis of $\mathrm{UFe}_{6} \mathrm{Ga}_{6}$ corresponds to the $c$-axis of $\mathrm{UFe}_{10} \mathrm{Si}_{2}$ according to the $14 / \mathrm{mmm}$-Immm groupsubgroup transformation.

The large saturation magnetization and particularly the large magnetic anisotropy of $\mathrm{UFe}_{6} \mathrm{Ga}_{6}$ suggest a significant contribution from the uranium atoms. However, this contribution cannot be clearly established without single crystal neutron diffraction experiments in untwined samples.

\section{Acknowledgements}

The authors wish to thank M. Armanda Sá from IFIMUP, University of Porto, for her collaboration in VSM measurements, and to Bente Lebech for her help in the neutron powder diffraction measurements. S. Sério acknowledges the FCT for a Post-Doc grant (SFRH/BPD/14545/2003). This work was partially supported by FCT (POCTI/CTM/38320/2001) and by the exchange Program PESSOA 2003-2004-GRICES/Embassade de France. 


\section{References}

[1] Li HS, Coey JMD. Magnetic properties of ternary rare-earth transitionmetal compounds. In: Buschow KHJ, editor. Handbook of magnetic materials, vol. 6. Amsterdam: North-Holland; 1991. p. 1.

[2] Buschow K.H.J. Novel permanent magnetic materials. In: Long GJ, Grandjean F, editors. Supermagnets, hard magnetic materials. Dordrecht: Kluwer; 1991. p. 49.

[3] Buschow KHJ, van der Kraan AM. J Phys F: Metal Phys 1978;8:921.

[4] Baran A, Suski W, Mydlarz T. J Less-Common Met 1984;96:269.

[5] Paixão JA, Lebech B, Gonçalves AP, Brown PJ, Lander GH, Burlet P, et al. Phys Rev B 1997;55:14370.

[6] Recko K, Biernacka M, Dobrzynski L, Perzynska K, Satula D, Szymanski K, et al. J Phys: Condens Matter 1997;9:9541.

[7] Gonçalves AP, Almeida M, Walker CT, Ray J, Spirlet JC. Mater Lett 1994;19:13.

[8] Gonçalves AP, Estrela P, Waerenborgh JC, Paixão JA, Bonnet M, Spirlet JC, et al. J Magn Magn Mat 1998;189:283

[9] Gonçalves AP, Almeida M, Amaro A, Godinho M, Paixão JA, Spirlet JC, et al. J Magn Magn Mat 1996;157-158:692.
[10] Waerenborgh JC, Figueiredo MO, Cabral JMP, Pereira LCJ. J Solid State Chem 1994;111:300

[11] International tables for crystallography, space-group symmetry, (Hahn T, editor), vol. A. D. Riedel Publishing Company, Dordrecht, 1983.

[12] Sheldrick GM. SHELX-97-program for crystal structure solution and refinement. Germany: Univ. Göttingen; 1997.

[13] Rietveld H. J Appl Cryst 1969;2:65.

[14] Brunner GO, Schwarzenbach D. Z Kristallogr 1971;133:127.

[15] Vainshtein BK, Fridkin VM, Indenbom VL. In: Modern crystallography II, structure of crystals, vol. 21. Berlin: Springer; 1982. p. 71.

[16] Kuznietz M, Gonçalves AP, Waerenborgh JC, Almeida M, Cardoso C, Cruz M, et al. Phys Rev B 1999;60:9494.

[17] Waerenborgh JC, Rogalski MS, Gonçalves AP, Sousa JB, Almeida M. Solid State Commun 1997;104:271.

[18] Weitzer F, Hiebl K, Rogl P, Grin YuN. J Appl Phys 1990;68:3512.

[19] Andreev AV, Nakotte H, de Boer FR. J Alloys Compd 1992;182:55.

[20] Waerenborgh JC, Gonçalves AP, Almeida M. Solid State Commun 1999; 110:369. 